\title{
Eruption Sequence Similarities in the Maxilla and Mandible
}

\author{
STANLEY M. GARN and B. HOLLY SMITH \\ Center for Human Growth \& Development, The University of Michigan, Ann Arbor, Michigan 48109
}

\section{J Dent Res (59)9:1534, September 1980}

Maxillary and mandibular dentitions exhibit correspondences to a truly remarkable degree. Correlations of upper and lower opponents (isomeres) in both the deciduous and permanent dentitions are exceeded only slightly by right-left (antimere) correspondences, both in crown size (Garn and Burdi, $J$ Dent Res 50:1407, 1971) and in tooth emergence timing (Garn and Smith, $J$ Dent Res, in press, 1980). Under these circumstances one might also expect inter-jaw correspondences in the order of tooth emergence, such that an $\mathrm{M} 2 \mathrm{P} 2$ or $\mathrm{P} 2 \mathrm{M} 2$ emergence order in one jaw would be associated with the same sequence in the opposing dentition.

To explore this possibility we have made use of two data sources, restricting data analysis to those boys and girls for whom sequences were completely clear for both upper and lower dentitions. The first dat a base, which we have extensively explored, is that of the Ten-State Nutritional Survey of 1968-1970 (Garn et al., J Dent Res 51:1506, 1972). The second data base includes the participants of the University of Michigan Longitudinal Study (Moyers et al., Standards of Human Occlusal Development, Ann Arbor, Center for Human Growth and Development, 1976). The first data base provides 220 black individuals and 284 white individuals, analyzed separately because of population differences in emergence sequence and timing. The second data base yields a total of 60 boys and

Received for publication January 15,1980

Accepted for publication February 8, 1980

This study was supported by grant DE 03610 from the National Institute of Dental Research. girls with unambiguous sequences (M2P2 or P2M2) in both jaws.

As shown in the table, there is an unquestionably large intra-individual correspondence between the M2P2/P2M2 eruption sequences in the mandible and maxilla. Although there are population differences in the incidences of the M2P2/P2M2 sequence polymorphism (as shown in the table) and possibly between the two series of white individuals, the trends are very much the same for all three subsamples, and all are highly significant by the Chi-squared tests. The children with the rarer $\mathrm{M} 2 \mathrm{P} 2$ sequence in the mandible (found in approximately $25 \%$ of cases) also tend to show the $\mathrm{M} 2 \mathrm{P} 2$ sequence in the maxilla. Conversely, boys and girls with the P2M2 sequence in the maxilla (where it is the overwhelming proportion) show a great excess of this sequence in the mandible as well. The strength of association ranges from .38 to .59 by the coefficient of contingency (C.C.). Attained Chi-squared values are between 30 and 115 ; the values are unusually high for samples in this size range and consistent for all three populations.

Thus synchronism in developmental sequence between the two jaws is confirmed. Despite differences in absolute timing of exuption of corresponding maxillary and mandibular teeth, and an intriguing gradient of precedence in eruption timing of upper and lower opponents (Israel et al., J Dent Res $46: 456,1967)$, the patterned developmental sequences that characterize the mandible (Garn et al., $J$ Dent Res 35:555, 1956) can now be shown to replicate in the maxilla. In addition to developmental "fields" controlling specific teeth, adjacent teeth, and antimeres, this new evidence indicates the existence of fields of synchronism in emergence orders affecting both jaws.

\begin{tabular}{|c|c|c|c|c|c|c|}
\hline \multicolumn{7}{|c|}{$\begin{array}{l}\text { TABLE } \\
\text { ASSOCIATION OF MAXILLARY AND MANDIBULAR ERUPTION SEQUENCES }\end{array}$} \\
\hline \multirow{3}{*}{$\begin{array}{l}\text { Mandibular } \\
\text { Sequence }\end{array}$} & \multicolumn{6}{|c|}{ Maxillary Sequence in } \\
\hline & \multicolumn{2}{|c|}{ Ten-State Blacks } & \multicolumn{2}{|c|}{ Ten-State Whites } & \multicolumn{2}{|c|}{ University Whites } \\
\hline & $\overline{\mathrm{M} 2 \mathrm{P} 2}$ & P2M2 & $\overline{\mathrm{M} 2 \mathrm{P} 2}$ & $\mathrm{P} 2 \mathrm{M} 2$ & $\overline{\mathrm{M} 2 \mathrm{P} 2}$ & P2M2 \\
\hline $\begin{array}{l}\text { M2P2 } \\
\text { P2M2 } \\
\text { Chi-squared }\end{array}$ & $\begin{array}{r}29 \\
4\end{array}$ & $\begin{array}{c}14 \\
173 \\
115^{*}\end{array}$ & $\begin{array}{r}17 \\
8\end{array}$ & $\begin{array}{c}33 \\
226 \\
48^{*}\end{array}$ & $\begin{array}{l}8 \\
0\end{array}$ & $\begin{array}{r}6 \\
46 \\
30 *\end{array}$ \\
\hline
\end{tabular}

*Significant at $p=.001$ or better, corresponding to a coefficient of contingency of $0.59,0.38$, and 0.58 , respectively. 